\title{
Options to accelerate ozone recovery: ozone and climate benefits
}

\author{
J. S. Daniel ${ }^{1}$, E. L. Fleming ${ }^{2,3}$, R. W. Portmann ${ }^{1}$, G. J. M. Velders ${ }^{4}$, C. H. Jackman ${ }^{2}$, and A. R. Ravishankara ${ }^{1}$ \\ ${ }^{1}$ National Oceanic and Atmospheric Administration, Earth System Research Laboratory, Chemical Sciences Division, \\ Boulder, CO 80305, USA \\ ${ }^{2}$ NASA Goddard Space Flight Center, Greenbelt, Maryland, 20771, USA \\ ${ }^{3}$ Science Systems and Applications, Inc., Lanham, MD 20706, USA \\ ${ }^{4}$ Netherlands Environmental Assessment Agency, 3720 AH Bilthoven, The Netherlands
}

Received: 23 March 2010 - Published in Atmos. Chem. Phys. Discuss.: 23 April 2010

Revised: 22 June 2010 - Accepted: 11 July 2010 - Published: 18 August 2010

\begin{abstract}
Hypothetical reductions in future emissions of ozone-depleting substances (ODSs) and $\mathrm{N}_{2} \mathrm{O}$ are evaluated in terms of effects on equivalent effective stratospheric chlorine (EESC), globally-averaged total column ozone, and radiative forcing through 2100. Due to the established success of the Montreal Protocol, these actions can have only a fraction of the impact on ozone depletion that regulations already in force have had. If all anthropogenic ODS and $\mathrm{N}_{2} \mathrm{O}$ emissions were halted beginning in 2011, ozone is calculated to be higher by about $1-2 \%$ during the period $2030-2100$ compared to a case of no additional restrictions. Direct radiative forcing by 2100 would be about $0.23 \mathrm{~W} / \mathrm{m}^{2}$ lower from the elimination of anthropogenic $\mathrm{N}_{2} \mathrm{O}$ emissions and about $0.005 \mathrm{~W} / \mathrm{m}^{2}$ lower from the destruction of the chlorofluorocarbon (CFC) bank. Due to the potential impact of $\mathrm{N}_{2} \mathrm{O}$ on future ozone levels, we provide an approach to incorporate it into the EESC formulation, which is used extensively in ozone depletion analyses. The ability of EESC to describe total ozone changes arising from additional ODS and $\mathrm{N}_{2} \mathrm{O}$ controls is also quantified.
\end{abstract}

\section{Introduction}

The Montreal Protocol on Substances that Deplete the Ozone Layer and its amendments and adjustments have been successful in halting the decline in global ozone (WMO, 2007); these actions have also reduced climate forcing from ozone-

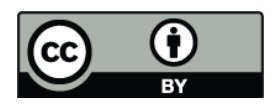

Correspondence to: J. S. Daniel (john.s.daniel@noaa.gov) depleting substances (ODS) over the last 2 decades (Velders et al., 2007), and have thus presumably reduced the rate of climate change over this period compared to what would have otherwise occurred. The production and consumption (defined by the Montreal Protocol as production plus imports minus exports) of many of the most important chlorine- and bromine-containing ODSs are already phased out. Most of the others are controlled, with schedules in place to phase out their production and consumption in the next few decades.

However, the Protocol does not limit some types of ODS production and consumption and does not directly regulate ODS emissions at all. Several activities involving ODSs are thus expected to continue to lead to atmospheric emissions. Restricting these sources represents an opportunity to accelerate ozone recovery. For example, because the Montreal Protocol does not directly regulate emissions, it does not limit the release of ODSs already produced and currently residing in existing equipment or applications, such as firefighting equipment, air conditioners, refrigerators, and foams. Production of hydrochlorofluorocarbons (HCFCs) and $\mathrm{CH}_{3} \mathrm{Br}$ also continues. Production of HCFCs is to be nearly phased out globally by 2030 with stepwise reductions in place in the intervening time under the current Protocol. $\mathrm{CH}_{3} \mathrm{Br}$ use for quarantine and preshipment purposes is unrestricted and critical use exemptions have been granted every year since 2005 (http://ozone.unep.org/Data_Reporting/ Data_Access/). Production of $\mathrm{CCl}_{4}$ for non-feedstock use has been globally phased out since the beginning of 2010. However, emissions resulting from its use as a feedstock, i.e. to produce another chemical, are unregulated; it is also coproduced during chloroform production and can be coproduced during perchloroethylene production (Sherry, 2004). These

Published by Copernicus Publications on behalf of the European Geosciences Union. 
unregulated $\mathrm{CCl}_{4}$ sources could explain why global emissions inferred from the $\mathrm{CCl}_{4}$ global lifetime and atmospheric mixing ratio observations have been higher than what has been suggested by reported production (WMO, 2007). Whatever the reason for this discrepancy, our inability to balance the $\mathrm{CCl}_{4}$ budget with current understanding of sources and sinks suggests that future trends are also uncertain and that emissions may continue.

Recently, it has been suggested that $\mathrm{N}_{2} \mathrm{O}$ could be considered an ODS (Ravishankara et al., 2009). While it has been known for over 4 decades that $\mathrm{N}_{2} \mathrm{O}$ leads to stratospheric $\mathrm{NO}_{\mathrm{x}}$ production and subsequent ozone destruction (Crutzen, 1970), $\mathrm{N}_{2} \mathrm{O}$ has not been regulated by the Montreal Protocol. Ravishankara et al. (2009) quantified the global ozone depletion potential (ODP) of $\mathrm{N}_{2} \mathrm{O}$ and compared the ODPweighted emissions of $\mathrm{N}_{2} \mathrm{O}$ with those of regulated ODSs. Such a comparison demonstrates that $\mathrm{N}_{2} \mathrm{O}$ is an important gas when considering ozone depletion. $\mathrm{N}_{2} \mathrm{O}$ is also a recognized greenhouse gas that was included in the basket of gases regulated under the Kyoto Protocol. Nevertheless, projections suggest that $\mathrm{N}_{2} \mathrm{O}$ emissions will remain significant through 2100 even under strongly mitigated climate stabilization scenarios (Clarke et al., 2007). While there has been widespread consensus that $\mathrm{N}_{2} \mathrm{O}$ is a substance that depletes ozone, some interpret that assigning a label of "ODS" to a compound implies a recommendation for regulation by the Montreal Protocol. Because such a recommendation cannot be justified by science alone, and because Ravishankara et al. (2009) did not make such a policy statement, we will not associate the label of ODS with $\mathrm{N}_{2} \mathrm{O}$ in the present study.

$\mathrm{CH}_{4}$ (Randeniya et al., 2002) and $\mathrm{CO}_{2}$ (Rosenfield et al., 2002) are also known to substantially affect ozone levels. Although increases in $\mathrm{CH}_{4}$ and $\mathrm{CO}_{2}$ are thought to lead to reduced ozone in certain regions of the stratosphere, calculations show that they lead to increases in total column ozone when globally averaged. Indeed, some calculations (Portmann and Solomon, 2007) suggest that future changes in these greenhouse gases over this century may lead to increases in globally averaged ozone levels that are large compared with the historical depletion experienced due to the ODSs. Owing to their climate impact, increasing $\mathrm{CH}_{4}$ and $\mathrm{CO}_{2}$ to increase stratospheric ozone is unlikely to be a viable policy option for reducing ozone depletion. Because of this, we do not consider such an option in the rest of this analysis. However, it should be noted that the results presented here must be considered against a backdrop of changing $\mathrm{CO}_{2}$ and $\mathrm{CH}_{4}$ levels, which will have significant global and regional impacts on ozone.

Equivalent effective stratospheric chlorine (EESC) (Daniel et al., 1995; Newman et al., 2007) has been the tool frequently used to quantify the relative effectiveness of various policy options for reducing ozone depletion (e.g., WMO, 1991, 1995, 1999, 2003, 2007). It has been assumed, but not explicitly quantified, that the integrated EESC decreases from some policy action are strongly related to the integrated ozone increases over the same time period. The EESC approach has been used partly because of the significant computer resources required to evaluate all available options directly using ozone calculated from 2-D or 3-D models. As computer speeds have increased, it has become feasible to perform these calculations with 2-D models.

Here, we consider several of the most important sources of future emissions that lead to ozone depletion and how additional controls could further limit this depletion and reduce radiative forcing. Emissions projections that incorporate reductions in these sources, along with the scenarios to which these are compared, are described in Sect. 2. Also in Sect. 2, we describe the models used to calculate ozone, and we present an approach to incorporate $\mathrm{N}_{2} \mathrm{O}$ into the global EESC formalism. In Sect. 3, the impacts of the various options for reducing future ODS and $\mathrm{N}_{2} \mathrm{O}$ emissions are calculated in terms of EESC, total column ozone, and radiative forcing. The ozone results are also used to quantify the extent to which the current EESC formulation serves as a suitable metric for approximating the impacts of ODS and $\mathrm{N}_{2} \mathrm{O}$ changes on integrated ozone changes. Conclusions are presented in Sect. 4.

\section{Analysis}

\subsection{Scenarios and hypothetical test cases}

Two reference scenarios are used to evaluate the various emission reduction cases. One, which we will refer to as the "background" includes no anthropogenic ODS or $\mathrm{N}_{2} \mathrm{O}$ emissions in the past or future; it does include observed $\mathrm{CO}_{2}$ and $\mathrm{CH}_{4}$ abundances through the present with future mixing ratios prescribed by the Intergovernmental Panel on Climate Change (IPCC) SRES A1B scenario (Nakicenovic et al., 2000). The background scenario also does not include the observed increase from 480 to 550 parts per trillion by volume (pptv) in $\mathrm{CH}_{3} \mathrm{Cl}$ during the 20th century (WMO, 2007). This increase may be due to natural processes, but plays a very minor role in the analysis. The second, "baseline", scenario includes the same $\mathrm{CO}_{2}$ and $\mathrm{CH}_{4}$ evolution as in the background scenario but also includes anthropogenic ODS and $\mathrm{N}_{2} \mathrm{O}$ emissions. Past concentrations are based on observations of the ODSs (WMO, 2007) and of $\mathrm{N}_{2} \mathrm{O}$ (http: //aom.giss.nasa.gov/IN/GHGA1B.LP). Future $\mathrm{N}_{2} \mathrm{O}$ concentrations are taken from the SRES A1B scenario. Future ODS concentrations are consistent with the current Montreal Protocol production and consumption limits. ODS concentrations are similar to those in case A1 of WMO (2007) except that they have been updated for more recent atmospheric observations (S. Montzka, personal communication, 2009) and, for some compounds, updated bank estimates (quantities residing in existing equipment or applications) (TEAP, 2009). A few additional changes relative to WMO (2007) include: (1) a reduction in future production of HCFCs, consistent 
with the faster phaseout approved by the Parties to the Protocol in 2007; and (2) a projected slower future decline in $\mathrm{CCl}_{4}$ production and emissions (5\%/yr) to obtain better consistency with the decline in emissions inferred from global mixing ratio observations over the last 4 years. Feedstock use and by-product emissions are not controlled by the Montreal Protocol. Emissions arising from these activities could grow and become increasingly important to future ozone depletion and climate; however, we will not consider any such growth because of the large uncertainty in their current and future contributions to emissions.

We consider seven hypothetical cases for reducing future ODS emissions. Some involve capture and destruction of the entire bank at the beginning of 2011, while others include a cessation of all future production from 2011 onward. $\mathrm{CH}_{3} \mathrm{Br}$ represents an exception in that emissions from gasoline, biomass, and biofuel burning are continued at $2007 \mathrm{lev}$ els (Yvon-Lewis et al., 2009) in all cases, even the $\mathrm{CH}_{3} \mathrm{Br}$ phaseout case. Continuing these burning byproduct emissions leads to a steady state $\mathrm{CH}_{3} \mathrm{Br}$ mixing ratio of $6.5 \mathrm{ppt}$ for the $\mathrm{CH}_{3} \mathrm{Br}$ phaseout case rather than the $5.3 \mathrm{ppt}$ attained if these emissions were also eliminated. We also assume that there is no bank for either $\mathrm{CCl}_{4}$ or $\mathrm{CH}_{3} \mathrm{Br}$, so a "no production" case would be identical to a "no emission" one for these compounds. For $\mathrm{N}_{2} \mathrm{O}$, elimination of all anthropogenic emissions beginning in 2011 is considered; this is implemented by having the mixing ratio enhancement above the natural background in 2011 decay with a global lifetime of 114 years (WMO, 2007) toward the background level of 275 parts per billion by volume (ppb) (Denman et al., 2007). All cases are run through 2100 . This end date is chosen partly for the practical reason that SRES scenario A1B and the ODS scenario, A1, are only projected through 2100 . It also becomes difficult to project market demand and emissions far into the future, particularly for compounds like $\mathrm{N}_{2} \mathrm{O}$ that are not currently individually regulated.

Complete elimination of each of these sources of future emissions is a straightforward way to demonstrate impacts on ozone and climate forcing. However, the feasibility and cost of reducing ODSs vary with compound and application. The effect of smaller reductions can be obtained by scaling to the results presented here; scaling is appropriate because the impacts are roughly linear with the magnitude of the phaseout as long as the reduction begins around 2011. The specific cases considered and the integrated reductions in ODS emissions from 2011-2050 relative to the baseline case are shown in Table 1, along with the impacts on EESC and ozone. The impacts will be discussed in Sect. 3 .

\subsection{Ozone calculations}

Ozone is calculated using the Goddard Space Flight Center (GSFC) (Fleming et al., 2007; Newman et al., 2009) and the NOCAR (Solomon et al., 1998; Portmann et al., 1999) interactive 2-D models with 2006 Jet Propulsion Laboratory
(JPL) rates (Sander et al., 2006). Both models successfully capture the processes important for calculating globally averaged total ozone. The agreement between models both in the calculated magnitude of ozone depletion and in the response of that depletion to ODS emission reductions gives us confidence in the results.

Recent 3-D modeling studies have shown the importance of climate change on future stratospheric projections (Eyring et al., 2007). To account for this, the GSFC model parameterizes the long-term changes in surface temperature, latent heating, and tropospheric $\mathrm{H}_{2} \mathrm{O}$ based on 3-D simulations from the Goddard Earth Observing System chemistryclimate model (GEOSCCM) (Pawson et al., 2008). The resulting 2-D simulation of the Brewer-Dobson circulation acceleration and decrease in stratospheric age-of-air over 1950-2100 is similar to that of the GEOSCCM. The GSFC 2-D model is also in good agreement with the GEOSCCM in simulating ozone and temperature changes over the 1950 2100 time period.

Both the GSFC and NOCAR models are forced with mixing ratio boundary conditions (BCs), as most models currently are. Ideally, emissions BCs could be used, but that would require a complete understanding of all loss processes for all compounds. Without this understanding, large errors in projected abundances and impacts on ozone could result. We note that none of the 3-D models used in the latest CCMVal report used emissions BCs (SPARC CCMVal, 2010). There are also some drawbacks to using mixing ratio BCs. As discussed in Douglass et al. (2008) mixing ratio BCs that are inconsistent with model loss processes can lead to highly unrealistic implied emissions. Mixing ratio $\mathrm{BCs}$ also constrain model responses in a way that prevents the model from accurately accounting for impacts such as changes in source gas lifetimes and changes in stratospheric $\mathrm{Cl}_{\mathrm{y}}$ evolution due to future circulation changes. However, for the purposes of this paper, this constraint is not critical. GSFC 2-D model simulations suggest that lifetimes will not change substantially in this century in response to projected greenhouse gas changes. For example, the $\mathrm{CCl}_{4}$ stratospheric lifetime is projected to decrease by $6 \%$ (51-48 years) from 2010-2100 (Rontu Carlon et al., 2010), and the lifetimes of CFC-11, CFC-12, and $\mathrm{N}_{2} \mathrm{O}$ are projected to decrease by 3$5 \%$ over this time period. Furthermore, the $\mathrm{N}_{2} \mathrm{O}$ distribution and other transport-sensitive features of both models compare well to observations (Garcia et al., 1992; Fleming et al., 2007), suggesting the transport calculations are sufficiently accurate for this study. The differences in lifetimes between these models and the one used to calculate the mixing ratio BCs would lead to erroneous inferred emissions, but estimating emissions is not a purpose of this paper.

For all scenarios, ODS emissions are calculated from production and bank projections in the same way as was done in WMO (2007); BC concentrations are then calculated from emissions using the box model described in WMO (2007). The tropospheric mixing ratio projections for the baseline 
Table 1. ODS and $\mathrm{N}_{2} \mathrm{O}$ phaseout cases considered and their impact on integrated EESC and globally averaged total column ozone (calculated by the GSFC model) relative to the baseline case. The "Bank" cases assume the entire bank present at the beginning of 2011 is captured and destroyed, but future production continues as in the baseline case. "Production" cases assume no future production of the compound beginning in 2011, but emissions from existing banks continue. "Emissions" cases assume no anthropogenic emission from 2011 onward. The "Total Emission Reduction" column contains the cumulative emission reduction from 2011-2050 compared to the baseline case. The integrated EESC and $\mathrm{O}_{3}$ change columns contain values for the reduction in these quantities relative to the baseline scenario for two time periods. The EESC percent changes are generally smaller than what has appeared in past ozone assessments partly because here the change is calculated relative to the entire anthropogenic EESC and because we include $\mathrm{N}_{2} \mathrm{O}$ contributions in EESC; in the assessments, the percentage change has been calculated relative to EESC in excess of 1980 EESC levels. If compared to EESC in excess of 1980 levels, 2011-2050 percentages here should be increased by more than a factor of 3. EESC is calculated assuming an age spectrum with a mean age and width of $3.0 \mathrm{y}$ and $1.5 \mathrm{y}$, respectively.

\begin{tabular}{lccccc}
\hline Case & $\begin{array}{c}\text { Total Emission } \\
\text { Reduction (Tg) }\end{array}$ & $\begin{array}{c}\text { Integrated EESC Change Relative } \\
\text { to Baseline Scenario (\%) }\end{array}$ & $\begin{array}{c}\text { Integrated } \mathrm{O}_{3} \text { Change Relative } \\
\text { to Baseline Scenario (\%) }\end{array}$ \\
\hline & $2011-2050$ & $2011-2050$ & $2011-2100$ & $2011-2050$ & $2011-2100$ \\
$\mathrm{~N}_{2}$ O Emission & $455^{1}$ & -5.6 & -15.9 & 0.35 & 0.79 \\
$\mathrm{CFC} \mathrm{Bank}$ & 1.32 & -2.5 & -2.9 & 0.13 & 0.14 \\
HCFC Bank & 3.44 & -1.0 & -0.7 & 0.07 & 0.03 \\
HCFC Production & 9.45 & -2.2 & -1.5 & 0.15 & 0.09 \\
Halon Bank & 0.09 & -2.5 & -2.4 & 0.15 & 0.12 \\
$\mathrm{CH}_{3}$ Br Emission & 0.49 & -1.5 & -1.9 & 0.09 & 0.09 \\
$\mathrm{CCl}_{4}$ Emission & 0.80 & -1.9 & -1.7 & 0.09 & 0.07 \\
$\mathrm{All} \mathrm{ODS} \mathrm{Emissions}^{2}$ & & -11.7 & -11.1 & 0.67 & 0.56 \\
\hline
\end{tabular}

\footnotetext{
${ }^{1}$ Determined directly from anthropogenic emissions provided for SRES A1B scenario. Value given in $\operatorname{TgN}_{2} \mathrm{O}$.

${ }^{2} \mathrm{CH}_{3} \mathrm{Br}$ emissions arising from gasoline, biomass, and biofuel burning are assumed to continue in the future at 2007 levels (Yvon-Lewis et al., 2009) in all scenarios except in the background scenario, in which these emissions are never included. If these emissions were eliminated, values for the $\mathrm{CH}_{3} \mathrm{Br}$ case in the table would be almost 3 times larger
}

scenario and mitigation cases are shown in Fig. 1 for some of the most important compounds. All production of the chlorine- and bromine-containing ODSs shown is projected to be near zero by or before mid-century. This strongly limits the benefits of any additional controls on future ODS production. The production of CFCs and halons is already very small, so the primary way to reduce emissions of these classes of ODSs involves capture and destruction of the banks. $\mathrm{N}_{2} \mathrm{O}$ projected emissions are different from those of the ODSs in that the $\mathrm{N}_{2} \mathrm{O}$ emissions are projected to remain near today's values through the end of the century in the baseline scenario.

\section{$2.3 \quad \mathrm{~N}_{2} \mathrm{O}$ and EESC}

$\mathrm{N}_{2} \mathrm{O}$ has not been included in EESC calculations before. There are important complications to including it because it participates in ozone destruction through the $\mathrm{NO}_{\mathrm{x}}$ cycle rather than the $\mathrm{ClO}_{\mathrm{x}}$ or $\mathrm{BrO}_{\mathrm{x}}$ cycles. Increasing $\mathrm{NO}_{\mathrm{x}}$ reduces the efficiency of $\mathrm{Cl}_{\mathrm{y}}$ and $\mathrm{Br}_{\mathrm{y}}$ for ozone destruction by tying up more of these halogens in the $\mathrm{ClONO}_{2}$ and $\mathrm{BrONO}_{2}$ reservoir species. At elevated chlorine and bromine levels, this offsets some of the impact of an increase in $\mathrm{N}_{2} \mathrm{O}$ on ozone depletion. Decreasing $\mathrm{Cl}_{\mathrm{y}}$ similarly ties up less $\mathrm{NO}_{\mathrm{y}}$ in $\mathrm{ClONO}_{2}$, increasing the efficiency of $\mathrm{N}_{2} \mathrm{O}$. These interactions imply that the projected future decline in $\mathrm{Cl}_{\mathrm{y}}$ and $\mathrm{Br}_{\mathrm{y}}$ abundances, resulting from the Montreal Protocol re- strictions, should lead to a greater impact of a unit change in $\mathrm{N}_{2} \mathrm{O}$ emissions on ozone (Ravishankara et al., 2009). On the other hand, since the loss of stratospheric $\mathrm{NO}_{\mathrm{y}}$ is inversely related to temperature, the efficiency of $\mathrm{N}_{2} \mathrm{O}$ for global ozone depletion is expected to decrease as the upper stratosphere cools from the projected increases in $\mathrm{CO}_{2}$ (Rosenfield and Douglass, 1998). From the 2-D models considered here, we estimate that by 2100 this process will result in a decrease of $10-20 \%$ in the effectiveness of a unit $\mathrm{N}_{2} \mathrm{O}$ emission to lead to ozone depletion compared with today. The effect of all of these interactions will potentially lead to a complicated relationship between EESC and ozone depletion. Nevertheless, we will suggest an approach for including $\mathrm{N}_{2} \mathrm{O}$ in EESC here and then quantify the success of this approach in Sect. 3. Future deviations of $\mathrm{CO}_{2}$ and EESC from the scenarios used here will alter the extent of these interactions; however, the deviations are not expected to be significant enough to substantively change the results.

Because our focus is on global ozone, we use the $\mathrm{N}_{2} \mathrm{O}$ global ODP to quantify $\mathrm{N}_{2} \mathrm{O}$ 's contribution to EESC. Ravishankara et al. (2009) calculated an ODP of 0.017 for 2000 conditions with the NOCAR model. We calculate a similar value of 0.019 for 2000 conditions with the GSFC model. When including $\mathrm{N}_{2} \mathrm{O}$, EESC can be written as 


$$
\begin{aligned}
& \operatorname{EESC}(t)=f_{\mathrm{CFC}-11} \cdot \\
& \left\{\begin{array}{c}
\sum_{\substack{\text { Cl-containing } \\
\text { compounds }}} n_{i} \frac{f_{i}}{f_{\mathrm{CFC}-11}}\left(\rho_{i, \text { entry }}-\rho_{i \text { (nat), entry }}\right) \\
+\alpha \sum_{\substack{\text { Br-containing } \\
\text { compounds }}} n_{i} \frac{f_{i}}{f_{\mathrm{CFC}-11}}\left(\rho_{i, \text { entry }}-\rho_{i, \text { (nat), entry }}\right) \\
+\xi \eta n_{\mathrm{N}_{2} \mathrm{O}} \frac{f_{\mathrm{N}_{2} \mathrm{O}}}{f_{\mathrm{CFC}-11}}\left(\rho_{\mathrm{N}_{2} \mathrm{O}, \text { entry }}-\rho_{\mathrm{N}_{2} \mathrm{O}, \text { (nat), entry }}\right)
\end{array}\right\}
\end{aligned}
$$

where $\alpha$ is the relative efficiency of bromine compared with chlorine for destroying total ozone and $\eta$ is the same factor for nitrogen relative to chlorine when the nitrogen originates from $\mathrm{N}_{2} \mathrm{O} . \eta$ is specifically for $\mathrm{N}$ originating from $\mathrm{N}_{2} \mathrm{O}$ because the efficiency of $\mathrm{N}$ production from $\mathrm{N}_{2} \mathrm{O}$ is included in its value. $\xi$ is a correction factor for $\eta$ that is discussed later, $n_{i}$ is the number of $\mathrm{Cl}, \mathrm{Br}$, or $\mathrm{N}$ atoms contained in the ODS, $f_{i}$ is the fraction of the compound dissociated on average in the stratosphere (assumed here to be for 3-yr-old age-of-air), and $\rho_{i}$ is the stratospheric entry mixing ratio in pptv, assumed to equal the tropospheric mixing ratio for these gases. We consider only the anthropogenic contributions of $\mathrm{N}_{2} \mathrm{O}, \mathrm{CH}_{3} \mathrm{Br}$, and $\mathrm{CH}_{3} \mathrm{Cl}$ by explicitly subtracting the tropospheric mixing ratio of each that arises from natural emissions $\left(\rho_{i, \text { nat }}\right)$. All concentrations arising from natural emissions are assumed to be constant in time, so we do allow the small increase in $\mathrm{CH}_{3} \mathrm{Cl}$ mixing ratios from WMO (2007) to increase EESC.

If we use the semiempirical ODP formula (Solomon et al., 1992)

$\mathrm{ODP}_{i}=\eta \frac{n_{i}}{n_{\mathrm{CFC}-11}} \frac{f_{i}}{f_{\mathrm{CFC}-11}} \frac{\tau_{i}}{\tau_{\mathrm{CFC}-11}} \frac{M_{\mathrm{CFC}-11}}{M_{i}}$

it follows that

$$
\begin{aligned}
\eta n_{\mathrm{N}_{2} \mathrm{O}} \frac{f_{\mathrm{N}_{2} \mathrm{O}}}{f_{\mathrm{CFC}-11}} & =\mathrm{ODP}_{\mathrm{N}_{2} \mathrm{O}} n_{\mathrm{CFC}-11} \frac{\tau_{\mathrm{CFC}-11}}{\tau_{\mathrm{N}_{2} \mathrm{O}}} \frac{M_{\mathrm{N}_{2} \mathrm{O}}}{M_{\mathrm{CFC}-11}} \\
& =6.4 \times 10^{-3}
\end{aligned}
$$

where $\tau_{i}$ is the global lifetime of compound $i$, and $M_{i}$ is its molecular weight. Levels of $\mathrm{ClO}_{\mathrm{x}}$ and $\mathrm{BrO}_{\mathrm{x}}$ were shown to significantly affect the $\mathrm{N}_{2} \mathrm{O}$ ODP in Ravishankara et al. (2009); at 1959 levels, the ODP was calculated to be 0.026 , compared with the 0.017 at 2000 conditions. We account for this dependence on the $\mathrm{N}_{2} \mathrm{O}$ term by applying a correction factor, $\xi$, in Eq. (1). This factor is assumed to be a linear function of the part of EESC arising from chlorine and bromine source gases so that the 1959 EESC level from these gases leads to a value for $\xi$ of $1.53(0.026 / 0.017)$ while the 2000 level of EESC leads to a value of 1.0. The 1959 and 2000 levels of EESC for the baseline scenario are 240 and 1640 pptv, respectively. This factor, along with Eq. (3), is then used in Eq. (1) to calculate $\mathrm{N}_{2} \mathrm{O}$ 's contribution to EESC. The EESC/ozone depletion relationship of the $\mathrm{N}_{2} \mathrm{O}$ phaseout case presented in Sect. 3 is more consistent with the other ODS cases when $\xi$ is included in Eq. (1).
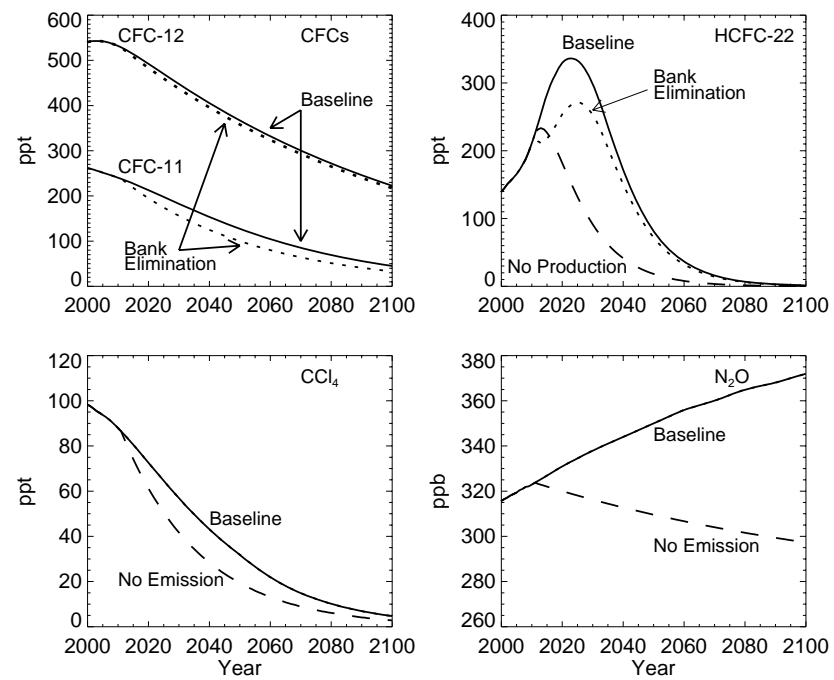

Fig. 1. Projected mixing ratios of $\mathrm{N}_{2} \mathrm{O}$ and selected ODSs for the baseline scenario and mitigation cases. Dotted curves (for CFCs and HCFC-22) represent mixing ratios assuming capture and destruction of the entire 2011 bank. Dashed lines represent mixing ratios assuming elimination of future production beginning in 2011 for $\mathrm{HCFC}-22$ and future emissions for $\mathrm{CCl}_{4}$ and $\mathrm{N}_{2} \mathrm{O}$.

By 2000, increases in $\mathrm{CO}_{2}$ had already cooled the stratosphere and reduced the $\mathrm{NO}_{\mathrm{y}} / \mathrm{N}_{2} \mathrm{O}$ ratio. Thus, when calculating $\xi$ using the 1959 and 2000 ODPs, this effect is included. The temperature effect is expected to scale differently with EESC in the future because EESC is projected to decrease while $\mathrm{CO}_{2}$ continues to increase in the A1B scenario; thus, these interactions should lead to some additional error in the correlation between EESC from $\mathrm{N}_{2} \mathrm{O}$ and the associated ozone depletion. However, this error is smaller than the benefit gained from including the EESC dependence in this simplified manner. We note that quantifying $\mathrm{N}_{2} \mathrm{O}$ 's contribution to EESC in this manner is appropriate for global ozone depletion only. The values for $f_{\mathrm{N}_{2} \mathrm{O}}, f_{\mathrm{CFC}-11}, \eta$, and $\xi$ would be different, for example, for the contribution of $\mathrm{N}_{2} \mathrm{O}$ to EESC relevant to the Antarctic ozone hole.

The age spectrum is applied to the EESC time series generated from Eq. (1), equivalent to applying it to each entry mixing ratio before the summation is applied. EESC is generally calculated here assuming a 3-year mean age and an age spectrum width of 1.5 years (Waugh and Hall, 2002) to represent the mean transport time between the troposphere and stratosphere. Relative fractional release values for 3-year-old air from Newman et al. (2007) are assumed for all compounds except for HCFC-141b and HCFC-142b, which were characterized by high uncertainty in that analysis. The relative values for these compounds are taken from WMO (2007). There has been discussion of a threshold in EESC below which changes in EESC have little or no impact on $\mathrm{O}_{3}$ (e.g., Daniel et al., 1995). Because calculated globally averaged total column ozone loss continues below this level, no threshold is considered here. 


\section{Results and discussion}

Figure 2 illustrates the maximum extent to which ODS and $\mathrm{N}_{2} \mathrm{O}$ emission phaseouts can accelerate the recovery of ozone and EESC towards a state defined by the emissions of no ODSs or anthropogenic $\mathrm{N}_{2} \mathrm{O}$ at any time. Even with full and immediate phaseouts of all ODS emissions, except for the three emission sources of $\mathrm{CH}_{3} \mathrm{Br}$ discussed in Sect. 2.1, the recovery to the background case will not have occurred by 2100 because of the long residence times of several of the ODSs and $\mathrm{N}_{2} \mathrm{O}$. Such a phaseout would, however, lead to ozone levels that exceed ozone in the baseline case by $1.2-1.9 \%$ between $2030-2100$. Chlorine and bromine emission reductions would affect $\mathrm{O}_{3}$ relatively quickly, with $\mathrm{N}_{2} \mathrm{O}$ playing a larger role by 2100 . To put this into perspective, relative to the background case, these models calculate a peak ozone depletion near 2000 of 7-8\% for the baseline case and a depletion of about $4 \%$ by 2100 . This peak depletion is substantially larger than the $3.5 \%$ quoted in WMO (2007) for the 2002-2005 time period because we are comparing to the higher $\mathrm{O}_{3}$ level calculated for the background case, which includes increases in $\mathrm{CO}_{2}$ and $\mathrm{CH}_{4}$ (and no ODSs), rather than to the 1964-1980 average observed ozone level used in WMO (2007). It has been estimated that in the absence of the Montreal Protocol, and assuming continued growth of ODSs, globally-average total ozone depletion could have reached $17 \%$ by 2020 and $67 \%$ by 2065 when compared to 1980 levels (Newman et al., 2009). So while options still exist to reduce future ozone depletion, the potential ozone impacts of additional controls are substantially reduced compared to what the Montreal Protocol has already achieved. Figure 2a also includes ground-based data from Fig. 3-2 in WMO (2007), allowing a comparison between the models and observations.

Figure 2a also shows the extent to which increases in $\mathrm{CO}_{2}$ and $\mathrm{CH}_{4}$ from the A1B scenario lead to higher calculated column ozone in these two models. Total ozone's return to 1980 levels is known to depend strongly on the future evolution of $\mathrm{CO}_{2}$ and likely on $\mathrm{CH}_{4}$ (Portmann and Solomon, 2007; Chipperfield and Feng, 2003; Rosenfield et al., 2002; Randeniya et al., 2002). However, as stated in the introduction, we do not consider $\mathrm{CO}_{2}$ or $\mathrm{CH}_{4}$ regulations to be policy options for reducing global ozone depletion. These gases are thought to have negative global ODPs, so their emissions would need to be increased to reduce ozone depletion. Such increases would lead to positive climate forcing.

One metric used in ozone assessments to evaluate the impacts of ODS emissions reductions is the year when EESC drops below the 1980 level. Figure 2 shows that this time associated with EESC, when calculated assuming a mean age of $3 y$, does not perfectly indicate when total ozone depletion due to ODSs returns to 1980 levels and that the relationship is model dependent. For the 2-D models used here, the evolution of future total ozone depletion due to ODSs is explained well by EESC, but EESC as calculated with a differ-
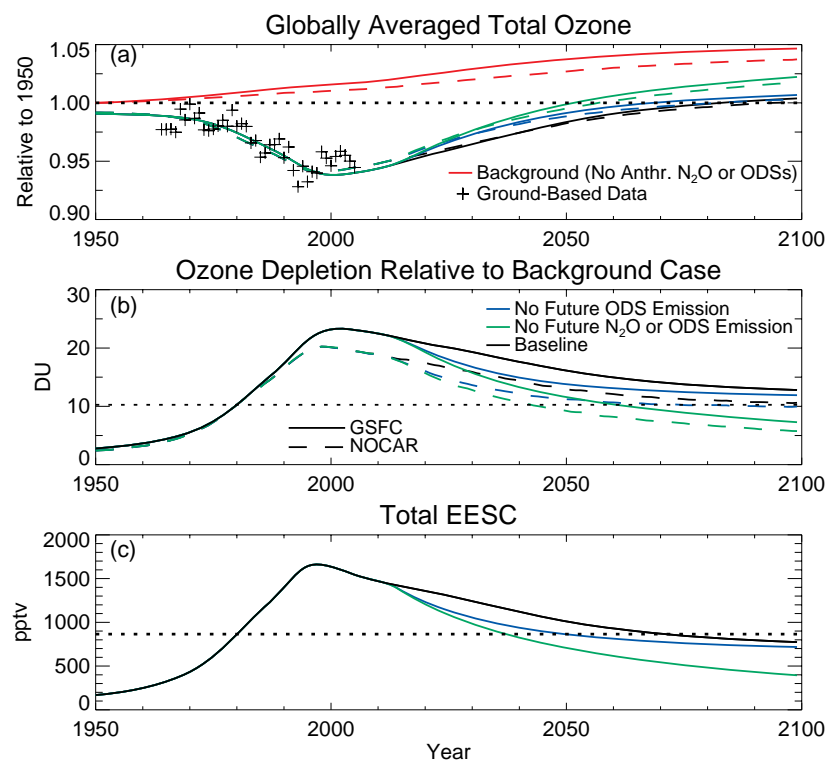

Fig. 2. (a) Globally averaged total column ozone, (b) ozone depletion relative to a case in which no anthropogenic $\mathrm{N}_{2} \mathrm{O}$ or ODSs were or will be emitted ("background" case), and (c) anthropogenic EESC time series including ODS and $\mathrm{N}_{2} \mathrm{O}$ contributions (calculated assuming an age spectrum with a $3.0 \mathrm{y}$ mean age, $1.5 \mathrm{y}$ width). Cases shown are the baseline scenario (black), in which future ODS emissions follow a path consistent with current growth and Montreal Protocol controls and IPCC scenario A1B for $\mathrm{N}_{2} \mathrm{O}, \mathrm{CH}_{4}$, and $\mathrm{CO}_{2}$; a case in which no anthropogenic ODSs are emitted after 2010 (blue); and a case in which no anthropogenic ODSs or $\mathrm{N}_{2} \mathrm{O}$ is emitted after 2010 (green). The ozone time series for the background case is also shown (red). Solid lines are calculations from the GSFC model; dashed are for the NOCAR model. "+" symbols represent ground-based total ozone data (WMO, 2007) normalized so the 1964-1980 average agrees with the model calculations. The dotted lines represent the 1980 benchmark levels; 1980 values are used in previous ozone assessments and are also often considered in Montreal Protocol discussions. In panel (b), the NOCAR ozone depletion is increased by $3 \%$ so the depletion in 1980 is identical for the two models. For example, this leads to an apparent maximum depletion relative to the background case in the NOCAR model of 20.3 DU rather than the actual 19.7 DU.

ent mean age and age spectrum width. When the average age and width are adjusted so the resulting EESC time series in the baseline scenario best matches the shape of the ozone depletion curves, we find the average ages for the NOCAR and GSFC results are $4.0 \mathrm{y}$ ( $2.4 \mathrm{y}$ width) and $5.5 \mathrm{y}$ ( $2.9 \mathrm{y}$ width), respectively. The high correlation for much of the time series between normalized EESC using these age spectra and ozone depletion is shown in Fig. 3. Fractional release values for the two EESC curves are calculated using the appropriate ages in the formulae of Newman et al. (2006) for all compounds except for HCFC-141b and HCFC-142b; those compounds are assumed to scale directly with CFC-11. The older bestfit ages imply that while EESC for 3-year-old air remains an 


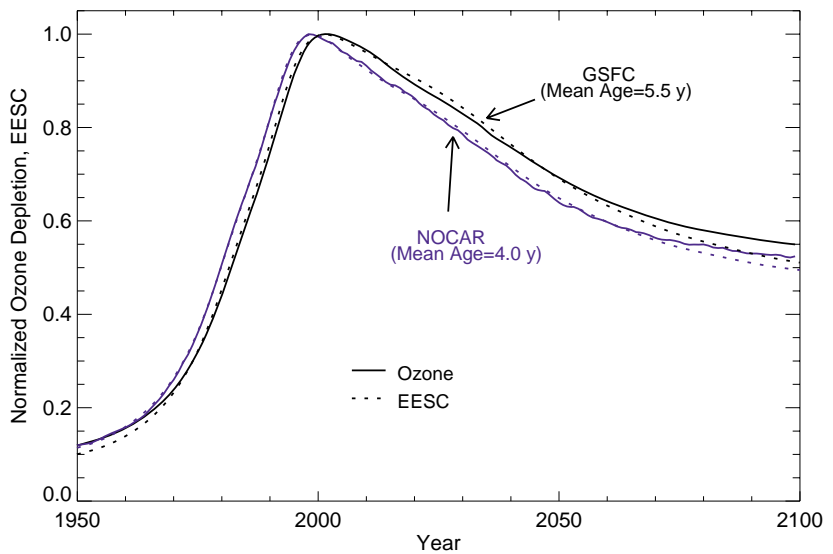

Fig. 3. Comparison of normalized ozone depletion from NOCAR (blue) and GSFC (black) models with EESC (dashed). Ozone depletion for each model is normalized to the maximum depletion, and EESC is normalized to its peak value. Age spectra used in the EESC calculations were determined by fitting the normalized EESC curves to the normalized ozone time series using a least-squares approach. Mean ages derived for the EESC fits are shown. Age spectra widths were found to be 2.4 and 2.9 years, respectively, for the NOCAR and GSFC calculations. The older characteristic age for the GSFC model is apparent.

acceptable and useful metric, it may not perfectly describe the evolution of globally averaged total column ozone or the time when ozone depletion will reach some target level even in the absence of changes in $\mathrm{CO}_{2}, \mathrm{CH}_{4}$, or other non-ODS emission or process. It is also important to recognize that the return of global total ozone to some approximately natural level does not imply that the ozone profile, the latitudinal variations, or the radiative forcing associated with the stratospheric ozone distribution will be the same as it was in the unperturbed state (WMO, 2007).

The effects of specific emissions reductions compared to the baseline scenario are quantified in terms of their effect on EESC, total ozone, and radiative forcing in Fig. 4. Table 1 also includes the effects on integrated EESC and ozone. Because each case involves an elimination of some future source of ODS emissions, the magnitude of the impact will be dependent on the amount of future emissions projected in the baseline scenario. For example, due to existing Montreal Protocol controls, by 2050 little emission remains in the baseline case for CFCs, Halons, $\mathrm{CCl}_{4}$, and HCFCs, with specific details depending on the compound. This explains the general shape of increasing impacts in the short run and then decreasing impacts with time for most of the cases. The $\mathrm{CH}_{3} \mathrm{Br}$ phaseout leads to a nearly constant change in EESC and ozone because of $\mathrm{CH}_{3} \mathrm{Br}$ 's short lifetime, combined with the assumed continuing QPS emissions in the baseline scenario.
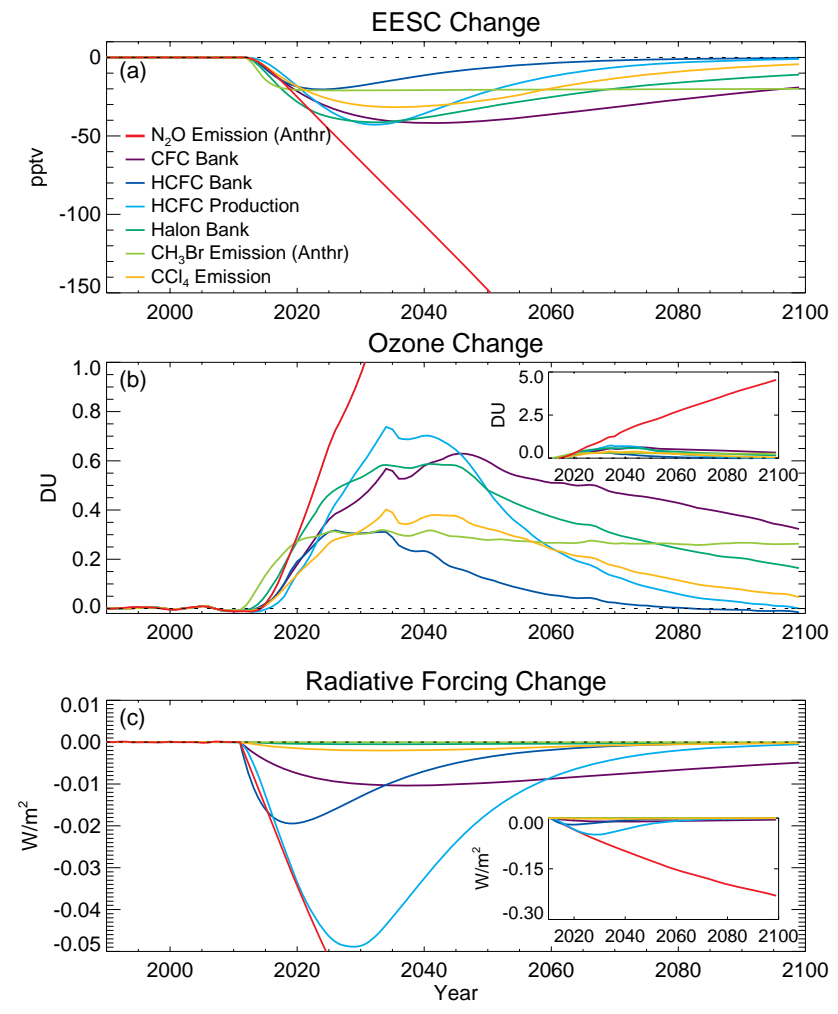

Fig. 4. Changes in (a) EESC, (b) total ozone from the GSFC model, and (c) radiative forcing, resulting from the various $\mathrm{N}_{2} \mathrm{O}$ and ODS reduction cases in Table 1 . The responses for the $\mathrm{N}_{2} \mathrm{O}$ case (red) appear almost linear in the main panels because of its long lifetime and because future anthropogenic $\mathrm{N}_{2} \mathrm{O}$ emissions vary little through 2100 in the assumed A1B scenario. The insets in panels (b) and (c) have increased vertical scale ranges so the entire $\mathrm{N}_{2} \mathrm{O}$ change is visible through 2100. EESC is calculated assuming an average age of $3.0 \mathrm{y}$ with an age spectrum width of $1.5 \mathrm{y}$.

The $\mathrm{N}_{2} \mathrm{O}$ anthropogenic emissions phaseout leads to increasing impacts on EESC, ozone, and radiative forcing over the time period shown, a fundamentally different response than that of the ODSs. This response results from the long lifetime of $\mathrm{N}_{2} \mathrm{O}$ and from its continuing emission in the baseline scenario, consistent with there being no current regulation that phases out its future emissions. Picking a longer time period will generally lead to greater relative importance of $\mathrm{N}_{2} \mathrm{O}$ emissions reductions compared with reductions of ODSs. To illustrate the importance of the time horizon considered, the integrated impacts in terms of EESC and ozone are shown for two time periods in Table 1. The larger relative impact of the $\mathrm{N}_{2} \mathrm{O}$ reduction over the longer period is clear. Of course, there is no scientific reason, and currently no policy reason, to stop the integration at 2100 , with ozone depletion still occurring relative to the background case. When dealing with a compound like $\mathrm{N}_{2} \mathrm{O}$, whose emissions are not limited in the future but are expected to continue indefinitely, the difficulties in choosing a time horizon 
for evaluating policy options are similar to those encountered when evaluating the relative impacts of greenhouse gases on radiative forcing and climate. An important distinction discussed below is that, unlike with climate change, it is possible that we could return to natural globally-averaged total column ozone levels in the next few decades, albeit with large regional differences (e.g., depletion continuing in the tropics vs. recovery in the extratropics).

The year 1980 has frequently been used as a reference year to evaluate progress towards ozone recovery, but it likely does not mark the onset of global ozone depletion (Jackman et al., 1996) (also see Fig. 2). If no consideration is given to ozone depletion after total EESC returns to 1980 levels, a value judgment is made to neglect the importance of some emissions that could still deplete $\mathrm{O}_{3}$ several decades from now. Choosing this threshold level and ignoring the contribution of $\mathrm{N}_{2} \mathrm{O}$ to EESC and ozone depletion in 1980, as has been typically done in the past, further obscures the relevance of a return to 1980 EESC levels. A related question is whether there is a level of global column ozone above which anthropogenic ozone depletion is no longer considered important. For example, if ozone column levels are still depleted due to the presence of ODSs, but they are higher than the globally-averaged natural level because of increases in $\mathrm{CH}_{4}$ and $\mathrm{CO}_{2}$, is ozone depletion still a concern? If such an acceptable level does exist, policy discussions will need to include the impact of future emissions of $\mathrm{CO}_{2}$ and $\mathrm{CH}_{4}$ on ozone. Because of the relevance of climate policy to these future emissions, this could represent an important linkage between climate and ozone policy.

Figure 4 also shows that the capture and destruction of the CFC bank leads to a greater ozone change than the other chlorine- and bromine-containing ODS cases after about 2045 , with an integrated ozone impact slightly larger than that of the Halon bank case from 2011-2100 (see Table 1). Even though the importance of these two banks to ozone is calculated to be similar, the Environmental Protection Agency estimates that in the United States of America the fraction of Halon banks that are technically accessible for capture and destruction $(>95 \%)$ is much greater than the fraction of the CFC banks ( $<10 \%)$ (Montzka et al., 2008). Accessibility is an important factor in determining the cost of bank capture. We make this point to emphasize that our calculations only indicate the importance of various emission sources to ozone and climate forcing; we make no estimate of the costs or even the relative costs of reducing future emissions.

The complete phaseout of anthropogenic $\mathrm{N}_{2} \mathrm{O}$ emissions leads to larger ozone and EESC changes than any other case considered from 2020-2025 onward, and its impact on integrated ozone and EESC from 2011-2100 is larger than all other cases combined. The relative importance of a phaseout in $\mathrm{N}_{2} \mathrm{O}$ emissions would become even greater beyond 2100. A phaseout of anthropogenic $\mathrm{N}_{2} \mathrm{O}$ emissions also has the greatest impact on radiative forcing (Fig. 4c). By the year 2100, an $\mathrm{N}_{2} \mathrm{O}$ phaseout would result in a radiative forcing about $0.23 \mathrm{~W} / \mathrm{m}^{2}$ less than in the baseline scenario. The capture and destruction of the entire CFC bank would lead to a reduction of about $0.005 \mathrm{~W} / \mathrm{m}^{2}$, and each of the other actions would reduce radiative forcing by less than $0.001 \mathrm{~W} / \mathrm{m}^{2}$ in 2100. In the shorter term, the HCFC bank and production cases lead to a radiative forcing change that is comparable to that of the $\mathrm{N}_{2} \mathrm{O}$ case over about the next 5 and 10 years, respectively. Although an $\mathrm{N}_{2} \mathrm{O}$ phaseout currently leads to the largest ozone and radiative forcing impacts of the cases considered, the Montreal Protocol has already resulted in large reductions in emissions of chlorine- and brominecontaining compounds. The associated reduction in direct radiative forcing due to the Protocol has been estimated to be $0.20-0.25 \mathrm{~W} / \mathrm{m}^{2}$ by 2010 compared to a case assuming unregulated growth (Velders et al., 2007). However, some of this benefit could be negated by future increases in hydrofluorocarbons (HFCs) used as replacements of CFCs and HCFCs (Velders et al., 2009).

In past ozone assessments, the impacts of additional ODS controls have been compared using EESC, integrated between either 1980 or the current time and the return of EESC to 1980 levels. It has been assumed that the integrated EESC decrease is proportional to the integrated ozone increase. The results in Table 1, integrated from 2011-2050, are used to evaluate the validity of this assumption, and the results are shown graphically in Fig. 5. The individual points, representing fractional EESC changes and fractional ozone changes, are not expected to fall exactly on a line because of known simplifications associated with the EESC formula and single values for $\eta, \alpha$, and $f_{i}$ in Eq. (1) that do not perfectly account for modeled processes that they are intended to represent. As seen in Fig. 3, uncertainties in dynamics and resulting transport times can also play a role in the ability of EESC to accurately represent ozone depletion. Two of the largest differences in integrated ozone changes between the two models are for the $\mathrm{CH}_{3} \mathrm{Br}$ and Halon cases as evident in Fig. 5. The lower impact on ozone depletion in the NOCAR model suggests that the representative $\alpha$ value is somewhat lower than 60 for that model. Daniel et al. (1999) calculated a value of 45 using the NOCAR model, but revised kinetics rates since that study have acted to raise this value some (WMO, 2007). In spite of all the potential causes of an imperfect relationship between EESC and ozone changes, the compact correlation shown in Fig. 5 demonstrates that the integrated ozone responses of the cases are represented quite well by the integrated EESC metric. The individual points for each model all fall within $30 \%$ of the linear fit for that model. If the age spectra from Fig. 3 are used instead of the mean of $3.0 \mathrm{y}$ and width of $1.5 \mathrm{y}$, the best-fit slopes of the two models are less similar. In that case, the slope of the NOCAR model fit is about -0.04 while the slope of the GSFC model fit is about -0.06 . But more important, for each model the individual cases remain within $\pm 30 \%$ of the best-fit lines. 


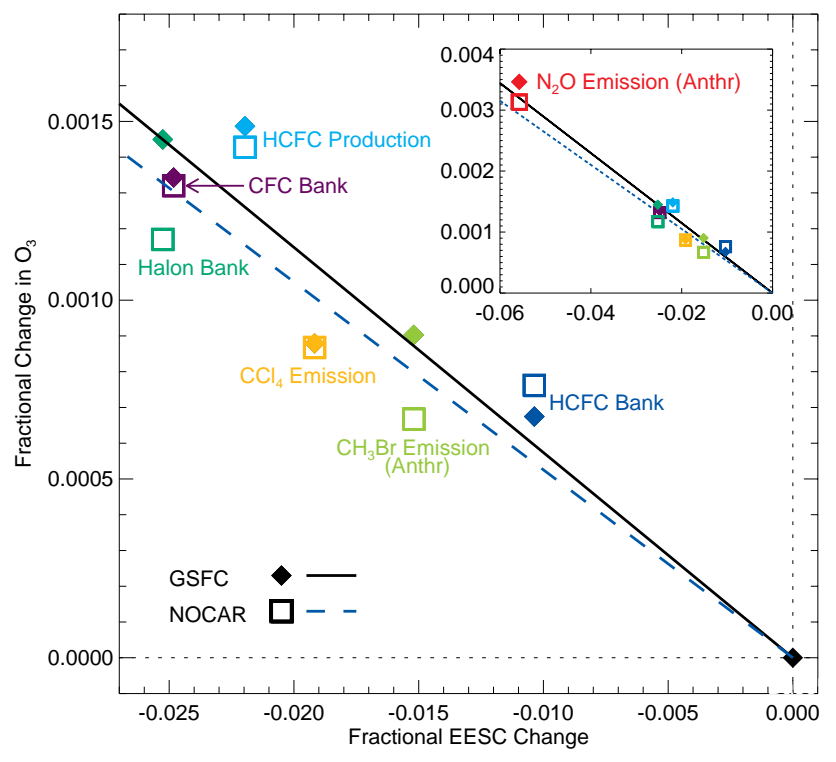

Fig. 5. Correlation of integrated EESC changes ( 3 y mean age) with integrated globally averaged total column ozone changes over the period 2011-2050. Ozone values are calculated by the GSFC (filled diamonds) and NOCAR (squares) models. The linear fits of the cases shown are also included (solid for GSFC; dashed for NOCAR). These fits are forced to go through the origin and do not include the $\mathrm{N}_{2} \mathrm{O}$ case (red symbols) in their calculation. The NOCAR slope (dashed blue) is less negative than the GSFC slope (solid black) primarily due to a smaller ozone change in the NOCAR bromine cases (green squares) than would be expected with an $\alpha$ of 60 . The inset shows the same information as the main figure with the scales expanded so the $\mathrm{N}_{2} \mathrm{O}$ emission phaseout case (red symbols) is visible.

The integrated EESC and ozone information from Table 1 is shown in an alternative way in Fig. 6. Here, the EESC change has been scaled by the slope of the line in the Fig. 5 fit to the GSFC results. If EESC were a perfect metric for evaluating ozone depletion in the models shown and all the constants used in Eq. (1) were accurate, each ozone bar would be expected to be the same size as the corresponding EESC bar. The similar sizes of the same-colored bars in Fig. 6 follow directly from Figs. 4 and 5 and demonstrate the degree to which EESC is a good metric for ozone. The similar sizes of the ozone response bars for the two models demonstrate their good agreement. The ozone bars are slightly smaller relative to the EESC bars in the lower panel than in the upper panel. However, the relative sizes of the ozone bars are still in good agreement with the relative sizes of the EESC bars, evidence that EESC is a good metric for quantifying the relative impacts of additional ODS controls on ozone during both of these time periods.
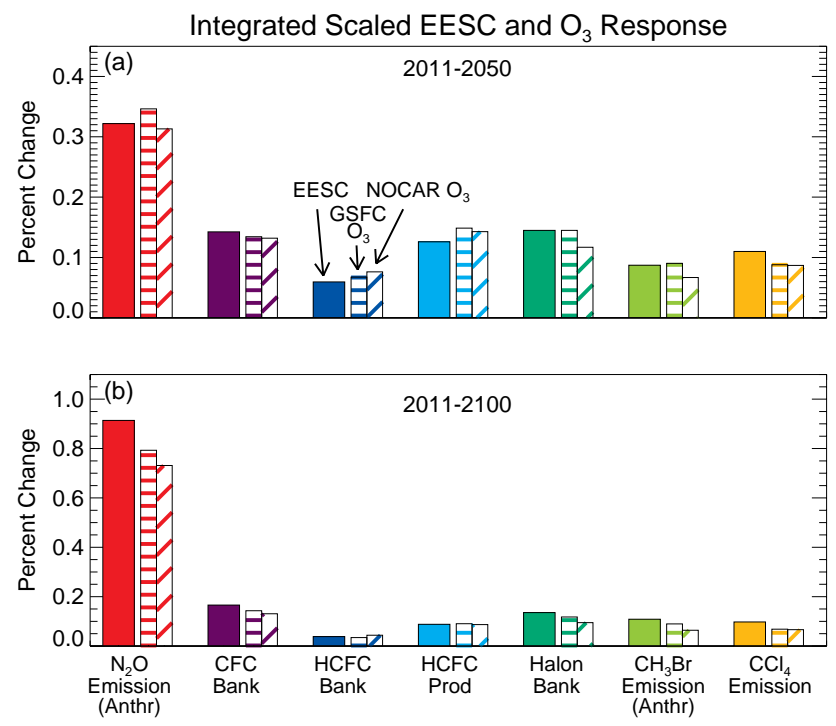

Fig. 6. Impact of the 7 hypothetical emissions reductions shown in Table 1 on integrated EESC (solid bars) and global total column $\mathrm{O}_{3}$ from GSFC (horizontal hatching) and NOCAR models (angled hatching). Integration periods of (a) 2011-2050 and (b) 2011-2100 are shown. The EESC changes are scaled by the slope of the linear fit to the GSFC calculations (solid black line) shown in Fig. 5. The extent to which ozone bars are the same height as the same-colored EESC bars (in the same panel) quantifies the success of the EESC parameterization in describing the integrated ozone response.

\section{Conclusions}

Hypothetical reductions in future $\mathrm{N}_{2} \mathrm{O}$ and ODS emissions from several potentially important sources have been analyzed for their impact on EESC, globally averaged total column ozone, and radiative forcing. The potential exists for accelerating future ozone increases and decreasing radiative forcing with additional ODSs and $\mathrm{N}_{2} \mathrm{O}$ controls. The impacts on ozone are expected to be substantially smaller than those already accomplished by the Montreal Protocol.

We have presented an approach for including tropospheric concentrations of $\mathrm{N}_{2} \mathrm{O}$ resulting from anthropogenic emissions into EESC. We have also demonstrated that integrated EESC is an effective proxy for integrated ozone changes for all emission reduction cases considered here, including the $\mathrm{N}_{2} \mathrm{O}$ case. Consistent with Ravishankara et al. (2009), we have shown that a complete phaseout of anthropogenic $\mathrm{N}_{2} \mathrm{O}$ emissions would have a larger impact on stratospheric ozone recovery than a combined phaseout of all anthropogenic chlorine- and bromine-containing ODSs when comparing the integrated effects to 2100 and neglecting potential future growth in ODS feedstock uses and byproduct emissions. $\mathrm{N}_{2} \mathrm{O}$ emission reductions have a relatively larger effect over longer integration times when compared with ODS reductions because of its long lifetime and projected continuing emissions throughout this century and beyond. This 
dependence on the time period considered raises the question of the level of concern devoted to ozone depletion if global ozone increases above the natural level in the coming decades, for example due to increasing $\mathrm{CO}_{2}$ and $\mathrm{CH}_{4}$, but depletion at some latitudes and altitudes still occurs.

Continuing anthropogenic $\mathrm{N}_{2} \mathrm{O}$ emissions assumed in the IPCC A1B scenario also play a larger role in future direct radiative forcing from about 2030 onward than the combined sources of all the future ODS emissions examined here. In the long term, an elimination of anthropogenic $\mathrm{N}_{2} \mathrm{O}$ emissions beginning in 2011 would reduce radiative forcing in 2100 by $0.23 \mathrm{~W} / \mathrm{m}^{2}$, while the most significant ODS emission reduction considered, the capture and destruction of the entire CFC bank, would lead to a reduction in radiative forcing of about $0.005 \mathrm{~W} / \mathrm{m}^{2}$ in 2100 . Over the next 5 and 10 years, respectively, the capture and destruction of the 2010 HCFC bank and the elimination of HCFC production from 2011 would lead to a radiative forcing change comparable to that of the $\mathrm{N}_{2} \mathrm{O}$ anthropogenic emission elimination.

In considering future $\mathrm{N}_{2} \mathrm{O}$ and ODS production or emission regulations, additional factors to those emphasized here will likely play a role as well, including for example, the economic cost associated with various regulations and the potential political tradeoffs of restricting some gases under the Montreal Protocol rather than under a climate agreement.

Acknowledgements. We appreciate the effort and comments of two anonymous reviewers, who have helped improve the manuscript. We thank S. Solomon for helpful discussions and comments. We thank V. Fioletov for making the ground-based ozone data used in WMO (2007) available for us to include. E. L. Fleming and C. H. Jackman were supported by the NASA Atmospheric Composition: Modeling and Analysis (ACMA) Program. Work at NOAA was funded in part by NOAA's Climate Program.

Edited by: W. Lahoz

\section{References}

Chipperfield, M. P. and Feng, W.: Comment on: Stratospheric ozone depletion at northern mid-latitudes in the 21st century: The importance of future concentrations of greenhouse gases nitrous oxide and methane, Geophys. Res. Lett., 30(7), 1389, doi:10.1029/2002GL016353, 2003.

Clarke, L., Edmonds, J., Jacoby, H., Pitcher, H., Reilly, J., and Richels, R.: Scenarios of Greenhouse Gas Emissions and Atmospheric Concentrations, Sub-report 2.1A of Synthesis and Assessment Product 2.1: Report by the U.S. Climate Change Science Program and the Subcommittee on Global Change Research, Department of Energy, Office of Biological \& Environmental Research, Washington, DC, 154 pp., 2007.

Crutzen, P. J.: The influence of nitrogen oxides on the atmospheric ozone content, Q. J. Roy. Meteorol. Soc., 96, 320-325, 1970.

Daniel, J. S., Solomon, S., and Albritton, D. L.: On the evaluation of halocarbon radiative forcing and global warming potentials, J. Geophys. Res., 100(D1), 1271-1285, 1995.
Daniel, J. S., Solomon, S., Portmann, R. W., and Garcia, R. R.: Stratospheric ozone destruction: The importance of bromine relative to chlorine, J. Geophys. Res., 104(D19), 23871-23880, 1999.

Denman, K. L., Brasseur, G., Chidthaisong, A., Ciais, P., Cox, P. M., Dickinson, R. E., Hauglustaine, D., Heinze, C., Holland, E., Jacob, D., Lohmann, U., Ramachandran, S., da Silva Dias, P. L., Wofsy, S. C., and Zhang, X.: Couplings between changes in the climate system and biogeochemistry, in: Climate Change 2007: The Physical Science Basis. Contribution of Working Group I to the Fourth Assessment Report of the Intergovernmental Panel on Climate Change, edited by: Solomon, S., Qin, D., Manning, M., Chen, Z., Marquis, M., Averyt, K. B., Tignor, M. and Miller, H. L., Cambridge University Press, Cambridge, UK and New York, USA, 2007.

Eyring, V., Waugh, D. W., Bodeker, G. E., Cordero, E., Akiyoshi, H., Austin, J., Beagley, S. R., Boville, B. A., Braesicke, P., Bruhl, C., Butchart, N., Chipperfield, M. P., Dameris, M., Deckert, R., Deushi, M., Frith, S. M., Garcia, R. R., Gettelman, A., Giorgetta, M. A., Kinnison, D. E., Mancini, E., Manzini, E., Marsh, D. R., Pawson, S., Pitari, G., Plummer, D. A., Rozanov, E., Schraner, M., Scinocca, J. F., Semeniuk, K., Shepherd, T. G., Shibata, K., Steil, B., Stolarski, R. S., Tian, W., and Yoshiki, M.: Multimodel projections of stratospheric ozone in the 21 st century, J. Geophys. Res., 112, D16303, doi:10.1029/2006JD008332, 2007.

Fleming, E. L., Jackman, C. H., Weisenstein, D. K., and Ko, M. K. W.: The impact of interannual variability on multidecadal total ozone simulations, J. Geophys. Res., 112, D10310, doi:10.1029/2006JD007953, 2007.

Jackman, C. H., Fleming, E. L., Chandra, S., Considine, D. B., and Rosenfield, J. E.: Past, present, and future modeled ozone trends with comparisons to observed trends, J. Geophys. Res, 101, 28753-28767, 1996.

Montzka, S. A., Daniel, J. S., Cohen, J., and Vick, K.: Current trends, mixing ratios, and emissions of ozone-depleting substances and their substitutes, in: Trends in Emissions of OzoneDepleting Substances, Ozone Layer Recovery, and Implications for Ultraviolet Radiation Exposure, edited by: Ravishankara, A. R., Kurylo, M. J., and Ennis, C. A., U.S. Climate Change Science Program and the Subcommittee on Global Change Research, Department of Commerce, NOAA's National Climatic Data Center, Asheville, NC, 29-78, 2008.

Nakicenovic, N., Alcamo, J., Davis, G., de Vries, B., Fenhann, J., Gaffin, S., Gregory, K., Grubler, A., Jung, T. Y., Kram, T., La Rovere, E. L., Michaelis, L., Mori, S., Morita, T., Pepper, W., Pitcher, H., Price, L., Riahi, K., Roehrl, A., Rogner, H.-H., Sankovski, A., Schlesinger, M., Shukla, P., Smith, S., Swart, R., van Rooijen, S., Victor, N., and Dadi, Z.: Special report on emissions scnearios: A special report of working group III of the Intergovenmental Panel on Climate Change, Cambridge University Press, Cambridge, UK, 599 pp., 2000.

Newman, P. A., Nash, E. R., Kawa, S. R., Montzka, S. A., and Schauffler, S. M.: When will the Antarctic ozone hole recover?, Geophys. Res. Lett., 33, 12, L12814, doi:10.1029/2005GL025232, 2006.

Newman, P. A., Daniel, J. S., Waugh, D. W., and Nash, E. R.: A new formulation of equivalent effective stratospheric chlorine (EESC), Atmos. Chem. Phys., 7, 4537-4552, doi:10.5194/acp7-4537-2007, 2007. 
Newman, P. A., Oman, L. D., Douglass, A. R., Fleming, E. L., Frith, S. M., Hurwitz, M. M., Kawa, S. R., Jackman, C. H., Krotkov, N. A., Nash, E. R., Nielsen, J. E., Pawson, S., Stolarski, R. S., and Velders, G. J. M.: What would have happened to the ozone layer if chlorofluorocarbons (CFCs) had not been regulated?, Atmos. Chem. Phys., 9, 2113-2128, doi:10.5194/acp-9-2113-2009, 2009.

Pawson, S., Stolarski, R. S., Douglass, A. R., Newman, P. A., Nielsen, J. E., Frith, S. M., and Gupta, M. L.: Goddard Earth Observing System chemistry-climate model simulations of stratospheric ozone-temperature coupling between 1950 and 2005, J. Geophys. Res., 113, D12103, doi:10.1029/2007JD009511, 2008.

Portmann, R. and Solomon, S.: Indirect radiative forcing of the ozone layer during the 21st century, Geophys. Res. Lett., 34(2), L02813, doi:10.1029/2006GL028252, 2007.

Randeniya, L. K., Vohralik, P. F., and Plumb, I. C.: Stratospheric ozone depletion at northern mid latitudes in the 21(st) century: The importance of future concentrations of greenhouse gases nitrous oxide and methane, Geophys. Res. Lett., 29(4), 1051, doi:10.1029/2001GL014295, 2002.

Ravishankara, A. R., Daniel, J. S., and Portmann, R.: Nitrous Oxide $\left(\mathrm{N}_{2} \mathrm{O}\right)$ : The Dominant Ozone-Depleting Substance Emitted in the 21st Century, Science, 326, 5949, 123-125, 2009.

Rontu Carlon, N., Papanastasiou, D. K., Fleming, E. L., Jackman, C. H., Newman, P. A., and Burkholder, J. B.: UV absorption cross sections of nitrous oxide $\left(\mathrm{N}_{2} \mathrm{O}\right)$ and carbon tetrachloride $\left(\mathrm{CCl}_{4}\right)$ between 210 and $350 \mathrm{~K}$ and the atmospheric implications, Atmos. Chem. Phys., 10, 6137-6149, doi:10.5194/acp-10-61372010, 2010.

Rosenfield, J. E. and Douglass, A. R.: Doubled $\mathrm{CO}_{2}$ effects of $\mathrm{NO}_{\mathrm{y}}$ in a coupled 2D model, Geophys. Res. Lett., 25, 4381-4384, 1998.

Rosenfield, J. E., Douglass, A. R., and Considine, D. B.: The impact of increasing carbon dioxide on ozone recovery, J. Geophys. Res.-Atmos., 107(D5-6), 4049, doi:10.1029/2001JD000824, 2002.

Sander, S. P., Friedl, R. R., Golden, D. M., Kurylo, M. J., Moortgat, G. K., Wine, P. H., Ravishankara, A. R., Kolb, C. E., Molina, M. J., Finlayson-Pitts, B. J., Huie, R. E., and Orkin, V. L.: Chemical kinetics and photochemical data for use in atmospheric studies evaluation number 15, National Aeronautics and Space Administration, Jet Propulsion Laboratory, Pasadena, California, 523 pp., 2006.
Sherry, D.: HFC-23, CFC, and PCB management and disposal 2000-2010, A study undertaken for the World Bank, 2004.

Solomon, S., Mills, M., Heidt, L. E., Pollock, W. H., and Tuck, A. F.: On the Evaluation of Ozone Depletion Potentials, J. Geophys Res., 97(D1), 825-842, 1992.

Solomon, S., Portmann, R. W., Garcia, R. R., Randel, W., Wu, F., Nagatani, R., Gleason, J., Thomason, L., Poole, L. R., and McCormick, M. P.: Ozone depletion at mid-latitudes: Coupling of volcanic aerosols and temperature variability to anthropogenic chlorine, Geophys. Res. Lett., 25(11), 1871-1874, 1998.

SPARC CCMVal: SPARC CCMVal report on the evaluation of chemistry-climate models, edited by: Eyring, V., Shepherd, T. G., and Waugh, D. W., SPARC Report No. 5, 2010.

TEAP: Task force decision XX/8 report, Assessment of alternatives to HCFCs and HFCs and update of the TEAP 2005 supplement report data, United Nations Environment Programme, Nairobi, Kenya, 2009.

Velders, G. J. M., Andersen, S. O., Daniel, J. S., Fahey, D. W., and McFarland, M.: The importance of the Montreal Protocol in protecting climate, P. Natl. Acad. Sci. USA, 104(12), 4814 4819, 2007.

Velders, G. J. M., Fahey, D. W., Daniel, J. S., McFarland, M., and Andersen, S. O.: The large contribution of projected HFC emissions to future climate forcing, P. Natl. Acad. Sci. USA, 106(27), 10949-10954, 2009.

WMO: Scientific Assessment of Ozone Depletion: 1991, Global Ozone Research and Monitoring Project, Geneva, Switzerland, 25,1991 .

WMO: Scientific Assessment of Ozone Depletion: 1994, Global Ozone Research and Monitoring Project, Geneva, Switzerland, Report 37, 1995.

WMO: Scientific Assessment of Ozone Depletion: 1998, Global Ozone Research and Monitoring Project, Geneva, Switzerland, Report 44, 1999.

WMO: Scientific Assessment of Ozone Depletion: 2002, Global Ozone Research and Monitoring Project, Geneva, Switzerland, Report 47, 2003.

WMO: Scientific Assessment of Ozone Depletion: 2006, Global Ozone Research and Monitoring Project, Geneva, Switzerland, Report 50, 2007. 